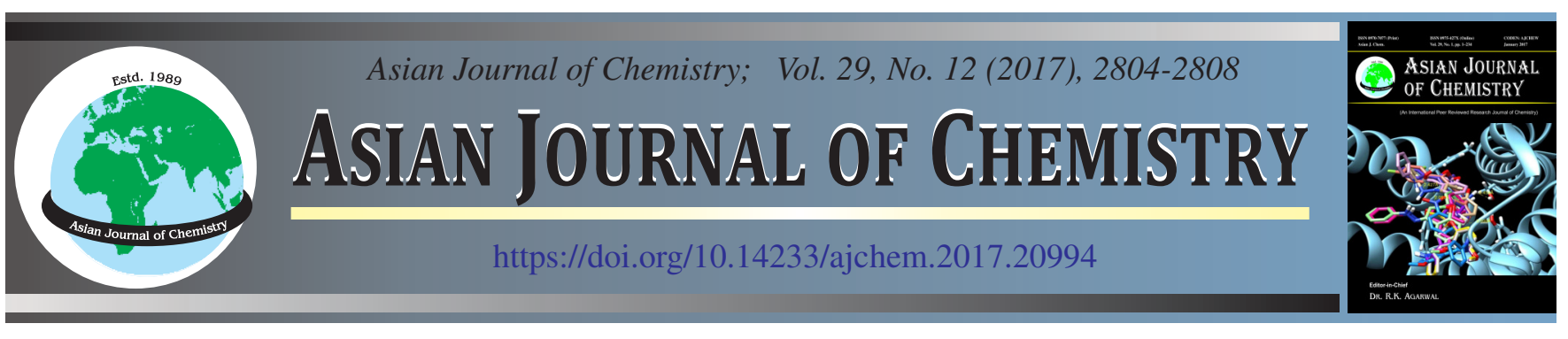

\title{
Synthesis and Characterization of Carbon Nanotubes by Modified Flame Fragments Deposition Method
}

\author{
Ali M. Jassm ${ }^{1}$, Falah H. Hussein ${ }^{2, *}$, Firas H. Abdulrazzak ${ }^{3}$, Ayad F. Alkaim $^{4}$ and Baker A. Joda ${ }^{1}$
}

${ }^{1}$ Department of Chemistry, College of Science, University of Karbala, Karbala, Iraq

${ }^{2}$ College of Pharmacy, University of Babylon, Hilla, Iraq

${ }^{3}$ Department of Chemistry, College of Education for Pure Sciences, University of Diyala, Baquba, Iraq

${ }^{4}$ Department of Chemistry, College of Science for Women, University of Babylon, Hilla, Iraq

*Corresponding author: E-mail: abohasan_hilla@yahoo.com

Received: 21 August 2017;

Accepted: 30 September 2017;

Published online: 30 October 2017;

AJC-18637

This study focuses on the synthesis of carbon nanotubes from Iraqi natural gas via a modified flame fragments deposition method in presence and absence of the catalyst. Four types of catalysts were used for the growth of carbon nanotubes. These types are iron doped on magnesium oxide $(\mathrm{Fe} / \mathrm{MgO})$, iron-cobalt doped on calcium carbonate $\left(\mathrm{Fe}-\mathrm{Co} / \mathrm{CaCO}_{3}\right)$ and iron(III) oxide. All these four types were prepared in one batch by a home made instrument. The implemented technique ensures the same experimental conditions such as type of carbon source, type of carrier gas, flow rate of gases, growth temperature and synthesis time of growth for all synthesized samples. Various experimental techniques viz., X-ray diffraction, Raman spectroscopy, scanning electron microscopy and thermogravimetric analysis were used for characterization of the synthesized carbon nanotubes.

Keywords: Carbon nanotubes, Flame fragments deposition, Natural gas.

\section{INTRODUCTION}

Carbon nanotubes (CNTs) can be described as a sheet of graphite rolled into a cylinder and has constructed from hexagonal rings of carbon and which were discovered first in1991 [1,2]. Carbon nanotubes have unique properties and because of large surface area, they have wide range of potential applications in many areas such as electron-field emitters in panel displays, singlemolecular transistors scanning probe microscope tips, gas, electrochemical energy storage, hydrogen storage, catalyst supports, molecular-filtration membranes, polymer fillers, strain sensors, chemical sensors high-power capacitors and quantum resistors [2,3]. Carbon nanostructures consist of numbers of shapes such as single-walled carbon nanotubes (SWCNTs), multiwalled carbon nanotubes (MWCNTs), nanobud, fullerenes and few-walled carbon nanotubes (FWCNTs) dependent on different diameters and structures $[4,5]$.

Carbon nanotubes are generally produced by three main techniques e.g., arc discharge, laser ablation and chemical vapour deposition (CVD) $[4,6,8]$. Chemical vapour deposition is considered of more the method using for increase large-scale production of graphite fibers and (multi-walled carbon nanotubes) compared to another of method due to the advantages in its low cost, high yield, direct control on the reaction parameters such as catalyst system, temperature, composition and flow rate of carbon precursor-carrier and hydrocarbon. Using transition metals (e.g., Ni-, and Co supported catalysts) as surface for growth carbon nanotubes and also using hydrocarbon such as (methane, ethane, acetylene, ethylene, natural gas, alcohols and other synthesis gas) as source for carbon [9-13].

In this article, a modified flame fragments deposition (FFD) method [14] is used for synthesizing carbon nanotubes from Iraqi natural gas.

\section{EXPERIMENTAL}

Home made flame fragments deposition instrument: The home made flame fragments deposition instrument is a stainless steelbox with dimensions $63.5 \mathrm{~cm} \times 42.5 \mathrm{~cm} \times 50 \mathrm{~cm}$. Natural gas, oxygen and nitrogen gases interned the system through three inlet stainless tubes with a diameter of $1.5 \mathrm{~cm}$. The flow rate of gases was controlled by outside gauges. The instrument consisted a gas gate for the excess gases. The upper lid is provided with thin cooling tubes with a length $9 \mathrm{~m}$ and $9 \mathrm{~mm}$ diameter with a cold water inlet and hot water outlet. On the top of the box there are seven stainless steel circulated sample collectors. These collectors are in touch with upper cold lid. The diameter of each circular collected position is $12 \mathrm{~cm}$. All 
seven positions are covered with thin foil. The schematic diagram of home made flame fragments deposition instrument is shown in Fig. 1.

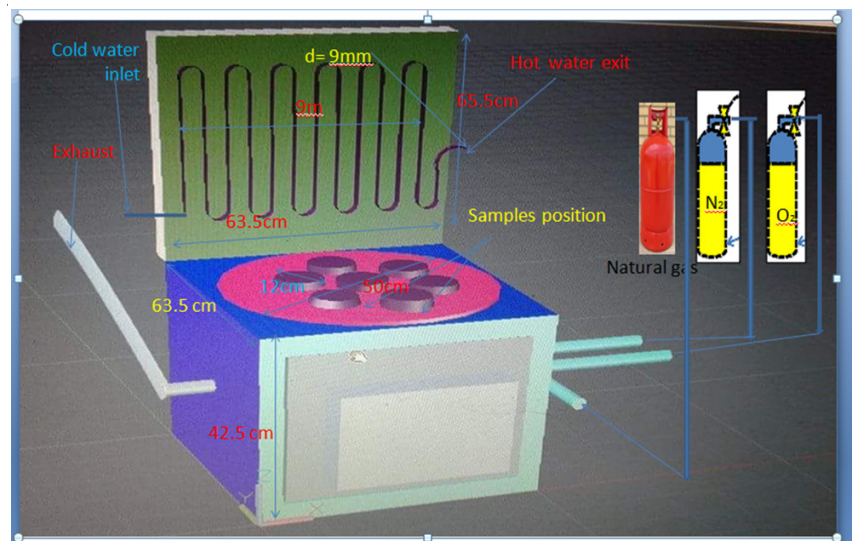

Fig. 1. Schematic diagram of home made flame fragments deposition instrument

Natural gas used as sources for carbon and oxygen gas in order to provide a natural combustion atmosphere for natural gas and nitrogen gas was used as inert gas and this gas helps to control the nature of combustion of natural gas. The process synthesis nanotubes in this way requires combustion to be incomplete for natural gas. After the gases entered the furnace, the combustion occurred, a yellow flame was formed, after which the nanotube deposition occurs on the surface of tin foil. The time required for complete process is $22 \mathrm{~min}$. The inside temperature in home made instrument is $140-150{ }^{\circ} \mathrm{C}$.

Purification of synthesized carbon nanotubes: Unique method is used for the purification of all synthesizd carbon nanotubes with four types of catalysts. The purification process involved several steps: (a) Removal of formed carbon nanotubes on surface tin foil paper by hot distilled water, (b) separation of carbon nanotubes from the mixture by separating funnel, (c) Drying of the synthesizd carbon nanotubes, (d) Refluxing with $5 \mathrm{M}$ of $100 \mathrm{~mL}$ nitric acid at $80^{\circ} \mathrm{C}$ for $7 \mathrm{~h}$ in order to remove the excessive catalyst, (e) remvoal of acid residue with distilled water for several times, (f) addition of $100 \mathrm{~mL}$ of ethanol to synthesizd carbon nanotubes, $(\mathrm{g})$ Drying of synthesizd carbon nanotubes in an oven at $70^{\circ} \mathrm{C}$ for $5 \mathrm{~h}$, (h) addition of $30 \mathrm{wt}$. \% $\mathrm{H}_{2} \mathrm{O}_{2}$ solution and finally stored in a refrigerator for $24 \mathrm{~h}$.

Raman microscopy: The samples were measured on a confocal Raman microscope Raman Microscopy System XploRATM (HORIBA JobinYvon, France). All samples were applied on a microscope slide without modification and measured at 5 different points with the same instrument setting. For measurement, a $532 \mathrm{~nm}$ laser was used with an intensity of $10 \%$ of the original laser beam focused on the sample with a $50 \times$ magnification (suitable for powder samples), a grid with 1200 scratches $/ \mathrm{mm}$ was used, the accumulation was set at $10 \mathrm{~s}$ and the number of replicates was 10. Spectra has been customized in Lab Spec software, part of Raman's XploRATM microscope.

X-ray Diffraction: X-ray diffraction powder diffractometer Rigaku UltimaIV with bagg-brentano arrangement, reflection method was used for analyses. The samples were placed on slide in rotary holder (no rotation), evaluation was made in PDXL2 program.
Thermal analysis: Thermogravimetric analysis were carried out on NETZSCH STA 409 EP. Samples (in the order of $101 \mathrm{mg}$ ) were heated to $1000^{\circ} \mathrm{C}$ by a heating rate of $10^{\circ} \mathrm{C} / \mathrm{min}$ in $\alpha-\mathrm{Al}_{2} \mathrm{O}_{3}$ crucibles in a dynamic air atmosphere at a flow rate of $100 \mathrm{~cm}^{3} / \mathrm{min}$.

Scanning electron microscopy: Extremely high-resolution SEM (sub nanometer resolution down to $1 \mathrm{keV}, 0.8 \mathrm{~nm}$ verified at $200 \mathrm{eV}$, operated down to tens of $\mathrm{eV}$ ) equipped with a cathode lens assembly, through-the-lens and side-attached electron detectors, four-channel retractable detector of BSE and six-channel retractable detector of TE, also equipped with EBSD, EDS (energy dispersive spectrometry of X-rays) and cathode luminescence attachments; standard vacuum conditions in a range of $10^{-5} \mathrm{~Pa}$, internal plasma cleaner.

\section{RESULTS AND DISCUSSION}

In this study, four carbon nanotubes were synthesized using four different types of catalysts viz., $\mathrm{Fe} / \mathrm{MgO}, \mathrm{Co}-\mathrm{MO} /$ $\mathrm{MgO}, \mathrm{Fe}_{2} \mathrm{O}_{3}$ and $\mathrm{Fe}-\mathrm{Co} / \mathrm{CaCO}_{3}$.

The XRD patterns (Fig. 2) of synthesized carbon nanotubes shows two groups of peaks: the first represents the characterized peaks of carbon nanotubes, while the second can be related to impurities. All the samples give the characteristic peaks of tubular structure of graphite at about $25^{\circ}$ and about $44^{\circ}$, which reported in many literatures at $23.5-23.8^{\circ}$ for pure carbon nanotubes [14-17] except for sample 4 . The peaks were shifted about $0.7^{\circ}-1.4^{\circ}$ as compare with average [16] of pristine multi-walled nanotubes which can be related to the impurities of all the samples. The difference between all the samples can be seen in the intensity and the width of characterizing peaks particularly at first peak at $25^{\circ}$. The typical peak at $25^{\circ}$ represents the characteristic graphitic peak arising due to the presence of the tubular structure of carbon atoms in the sample with (002) planes. The ratio of impurities for sample 4 was very high which prevent to shows carbon nanotubes.

The second group of peaks at 15, 23.5, 26.5, 33, 37, 44.5, $\left.51,54,57,62,64,68^{\circ}\right]$ is due to the impurities, probably refer to $[\mathrm{Fe}, \mathrm{Al}, \mathrm{Mg}, \mathrm{Co}$, confirming the surface of precipitation.

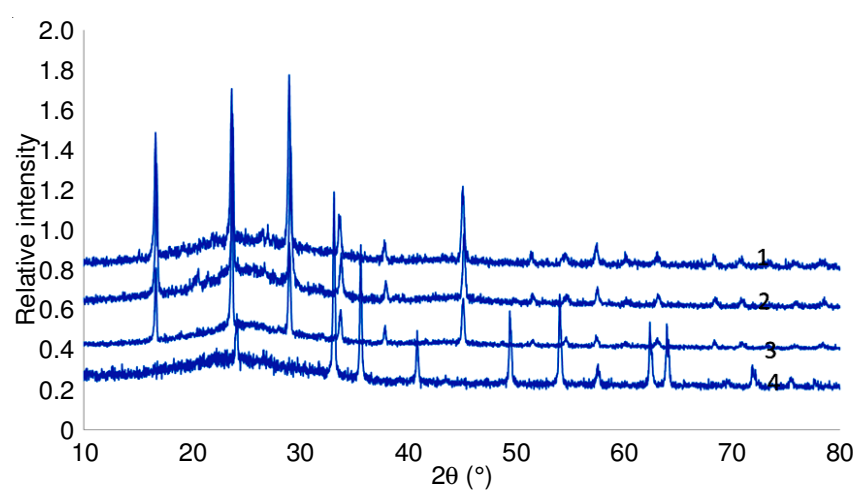

Fig. 2. XRD patterns of the samples

The identification peaks for carbon nanotubes on Raman spectra are $\mathrm{D}$ and $\mathrm{G}$ bonds at 1350 and $1570 \mathrm{~cm}^{-1}$, respectively with accuracy $\pm 30 \mathrm{~cm}^{-1}$ (Fig. 3). The D attributed to disorder carbon atoms of carbon nanotubes corresponding to $s p^{3}$ while $\mathrm{G}$ is related to $s p^{2}$ hybridization [15]. Raman spectroscopy for the samples shows that only four samples S1, S2, S3 and S4 

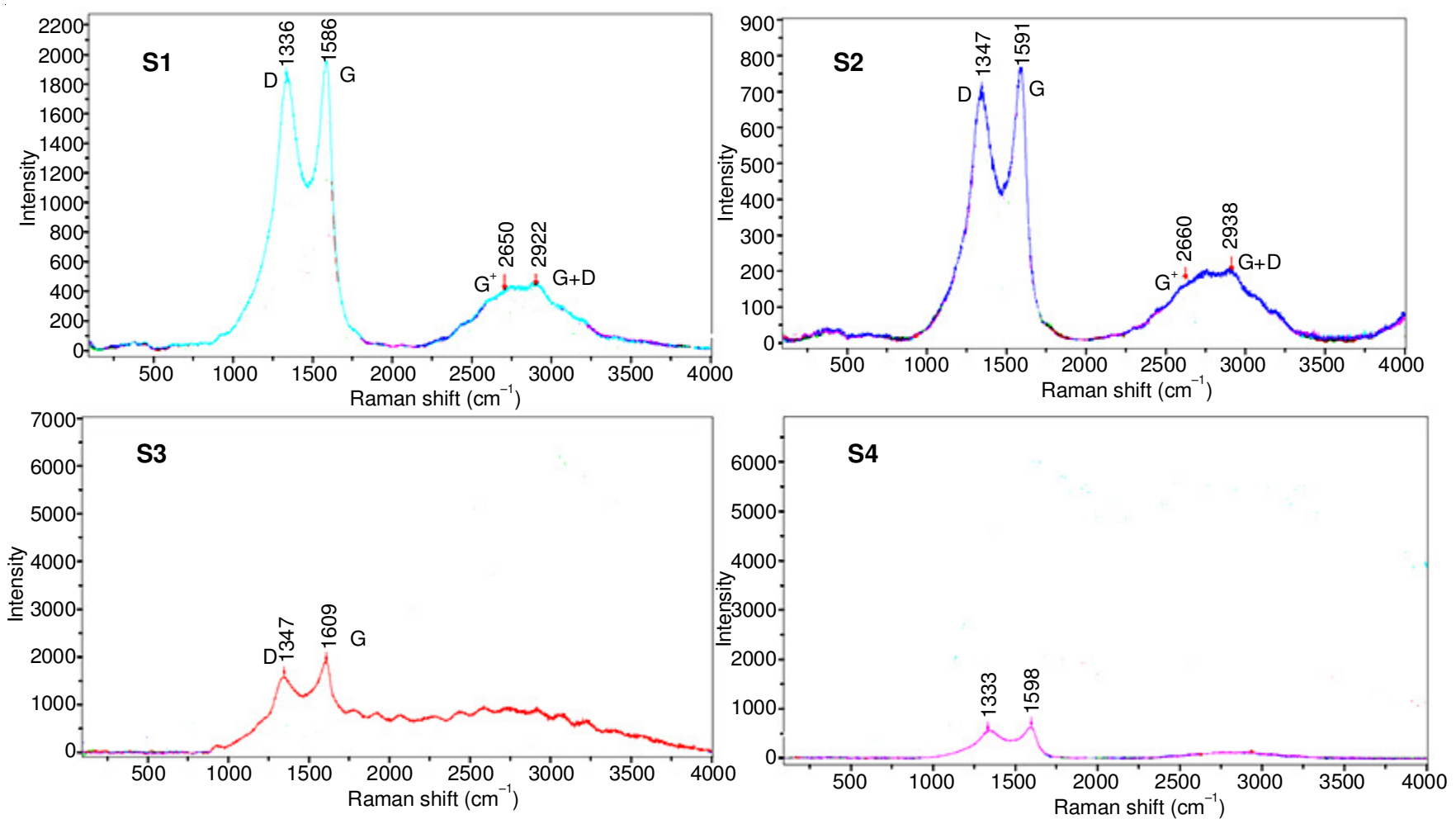

Fig. 3. Raman spectra for $\mathrm{S} 1, \mathrm{~S} 2, \mathrm{~S} 3$ and $\mathrm{S} 4$

refer to exist of carbon nanotubes while no signals were shown for $\mathrm{S} 4$. The variant in the intensities of $\mathrm{G}$ and $\mathrm{D}$ peaks can be related to the nature of tubes, types and ratios of impurities. The $\mathrm{I}_{\mathrm{D}} / \mathrm{I}_{\mathrm{G}}$ ratio refer to the type of carbon nanotubes when the higher values from 1 unit indicate a weak structure with more distortion on the surface. The values of $\mathrm{I}_{\mathrm{D}} / \mathrm{I}_{\mathrm{G}}$ was $0.84,0.87,0.92$ and 1.08 for S1, S2, S3 and S4, respectively. In addition, it can be seen that $\mathrm{S} 1$ and $\mathrm{S} 2$ shows two weak peaks at about 2920 and $2620 \mathrm{~cm}^{-1}$ which are related to $\mathrm{G}+\mathrm{D}$ and $\mathrm{G}^{+}$band, respectively. The last two samples S3 and S4 shows removal of two peaks completely with kept the weak bands $\mathrm{G}$ and $\mathrm{D}$ for $\mathrm{S} 3$ as shown in Fig. 3 with no carbon nanotubes in S4.

The SEM images for synthesized sample shows clearer images with ratios of impurities which explained in thermogravimetric analysis for the best three samples. The best images were shown for the synthesized carbon nanotubes for S1 and S2 which refer to MWCNT (Figs. 4 and 5). The outer and inner diameter of S1 was 18 and $34 \mathrm{~nm}$ while for S2 was $20 \mathrm{~nm}$ and $27 \mathrm{~nm}$. The images of SEM refers to MWCNTs for S1 and FWCNTs with S2 [18]. The number of graphene layers were more than six sheets for $\mathrm{S} 1$ and 2-4 sheets for $\mathrm{S} 2$. The reason is attributed due to the thickness of deposited metal film on the substrate [19]. The sample S3 shows (Fig. 6) few filaments signalled by red circles which make accumulation with unconverted carbon and particles of catalyst, however it refer to law ratios of sample.

Thermogravimetric analysis: For S1, at $100-180^{\circ} \mathrm{C}$, there is a mass loss of approximately $9.73 \%$ which can be attributed to the evaporation of adsorbed water and alcohol, which may adsorbed during washing of samples [20]. The range between $200-350{ }^{\circ} \mathrm{C}$ appears to the loose mass $\sim 8.08 \%$ and is associated with an endothermic release in the DSC signal, typical of a

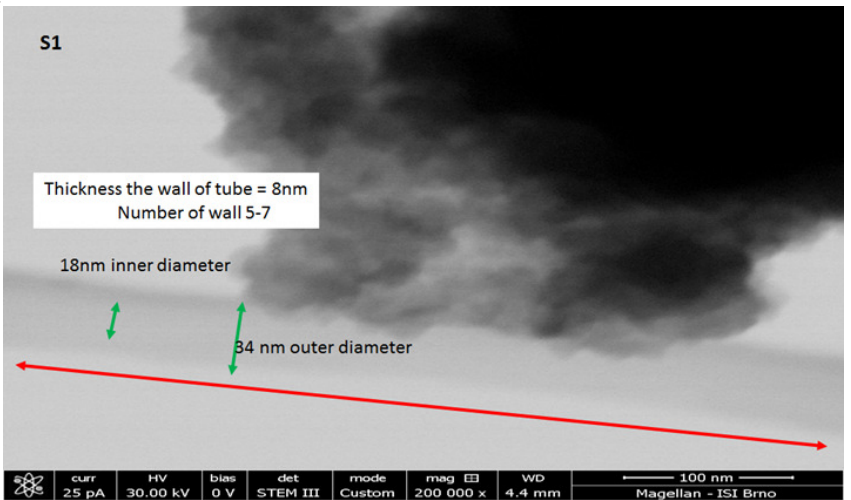

Fig. 4. SEM image for S1 of MWCNTs

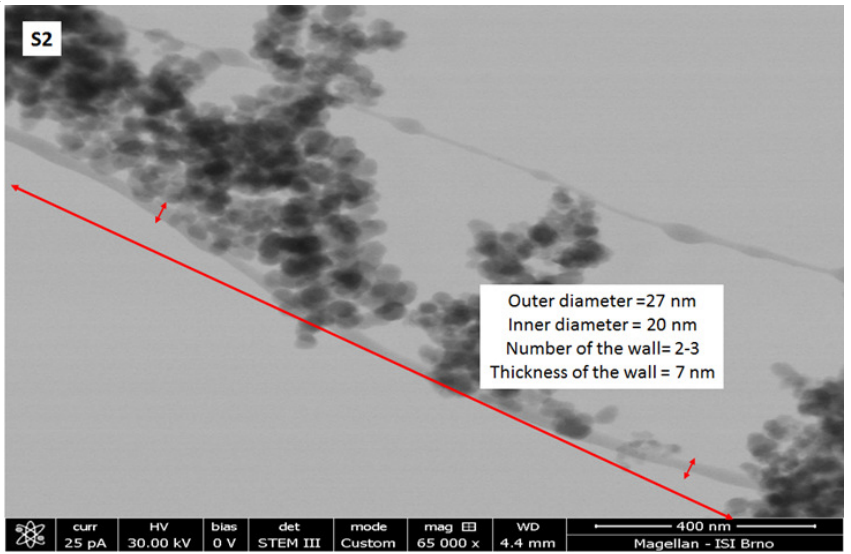

Fig. 5. SEM image for S2 of MWCNTs

decompositon/evaporation/sublimation event. This behaviour has also been observed by previous researchers [21] which is related to heavy organic materials introduced at the end of the 


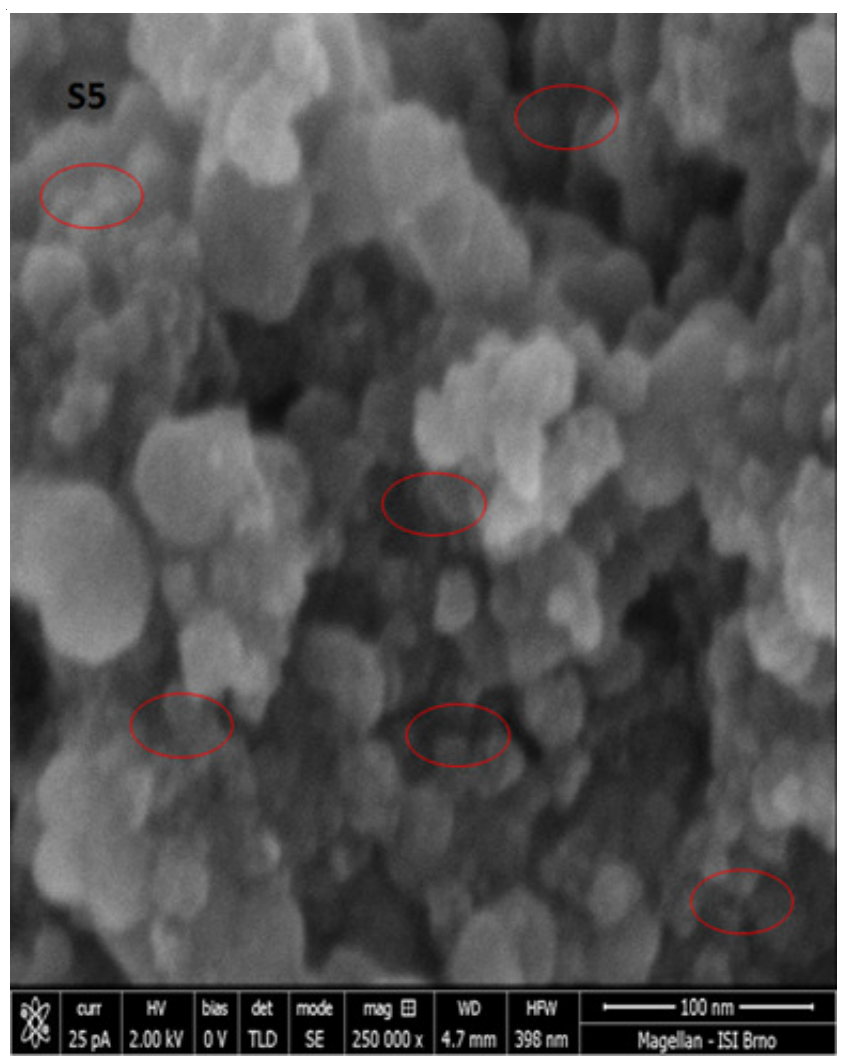

Fig. 6. SEM image for S3 of MWCNTs

synthesis process) (in addition to amorphous carbon which appears after more than $150{ }^{\circ} \mathrm{C}$ to about $400^{\circ} \mathrm{C}$. The third part, which includes the range $410-520^{\circ} \mathrm{C}$, shows the lose of $54 \%$ mostly refer to MWCNTs and an exothermic peak in DSC signal [22]. After $520^{\circ} \mathrm{C}$ refer to $30 \%$ for the remaing material which mostly refer to the impurties.

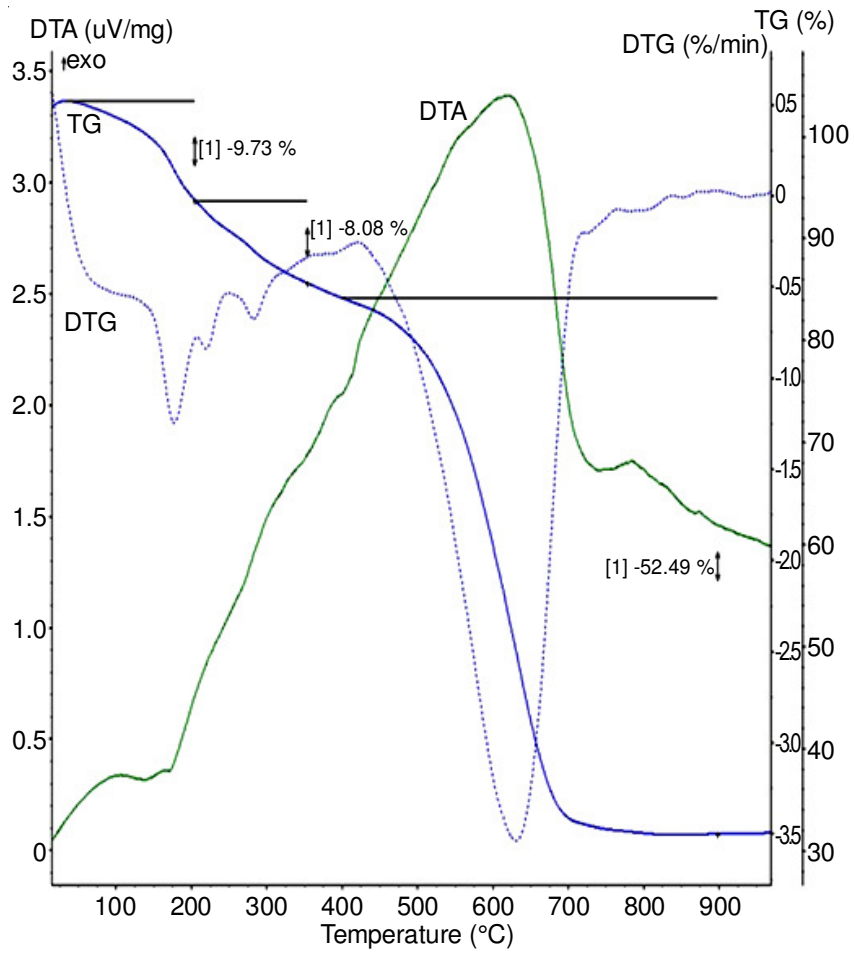

Fig. 7. TG, DTG and DTA curves of thermal degradation of sample 1
The mass loss behaviour of sample 2 was very similar to sample 1, except sample 2 began to loose mass slightly earlier in the last step with the major mass loss occuring between $350-470{ }^{\circ} \mathrm{C}$ with additional changes in mass loss rate that correspond to the small peaks that appear after the large DSC peak. This behaviour can be related to nature of precipetation when the $\% \mathrm{C}$ that make it less regular with increasing the amorphous carbon in sample 2 . The total mass loss observed by heating sample 2 to $1000{ }^{\circ} \mathrm{C}$ is $40 \mathrm{wt} \%$ mostly the analysis refer to FWCNTs [21]. In addition to $11.11 \%$ for adsorbed water at $\mathrm{T}<150{ }^{\circ} \mathrm{C}$ and $10.07 \%$ for unconverted carbon at $\mathrm{T}$ $<3000{ }^{\circ} \mathrm{C}$ with more than $40 \%$ for impurties (Fig. 8).

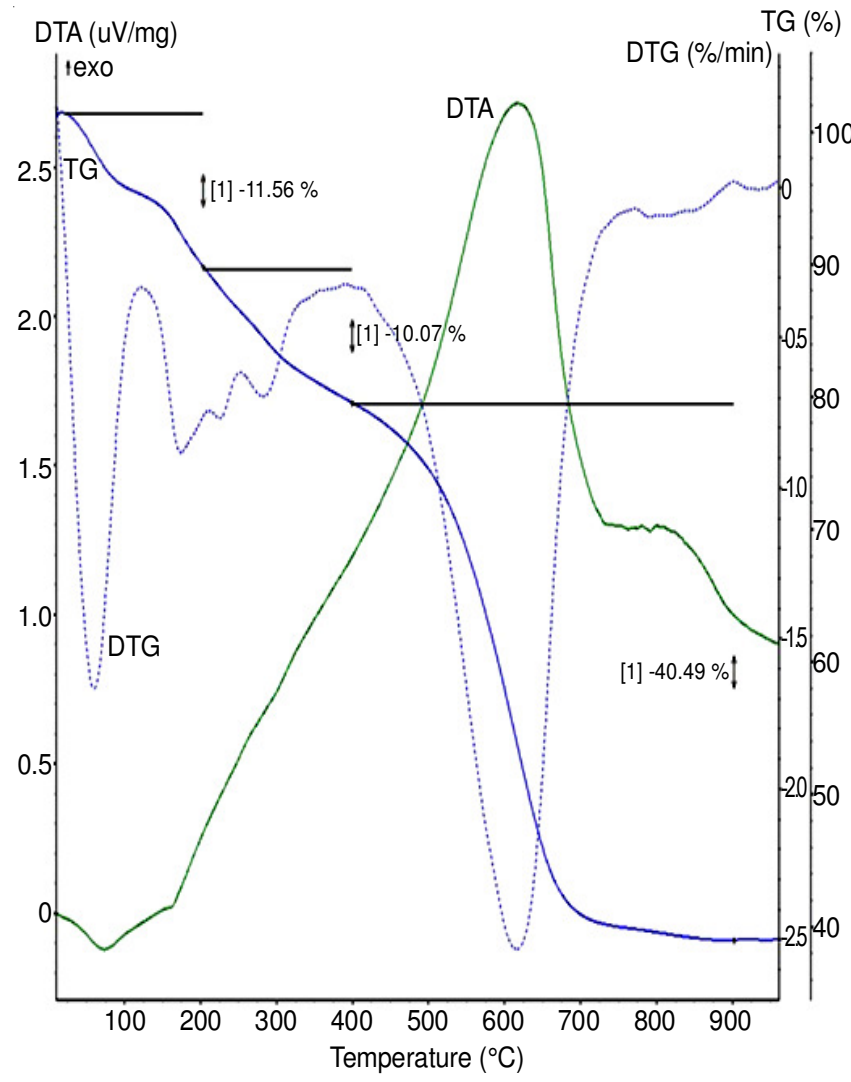

Fig. 8. TG, DTG and DTA curves of thermal degradation of sample 2

Sample 3 also began to loose mass upon heating but did not experience mass loss as much starting at $165^{\circ} \mathrm{C}$ as compared to samples 2 and 3. The first reduces in mass was $11.07 \%$ for adsorbant water and $13 \%$ for unconverted carbon at $\mathrm{T}<120$ ${ }^{\circ} \mathrm{C}$ and $\mathrm{T}<260^{\circ} \mathrm{C}$, respectively (Fig. 9). Most of the mass loss is intitiated at $300{ }^{\circ} \mathrm{C}$ with $50 \mathrm{wt} \%$ lost between $300-500{ }^{\circ} \mathrm{C}$ which related to decomposition of synthesized MWCNTs [23] and other carbon nanoparticles. After cooling, $37 \mathrm{wt} \%$ of the sample left, which can be related to the remaining catalyst. Therefore, the ratios of MWCNTls mostly less then $20 \%$ due to law thermal stablities which accured at $>300{ }^{\circ} \mathrm{C}$.

As a results the nature of precipitation influence directly with the different types of catalyst and the distribution of binary and ternary mixture catalyst on the surfaces of support. Thus pristine iron oxide shows variant in abilities to bulid tubular structure from carbon as free radicals when compare with iron oxide in mixture of catalyst. 


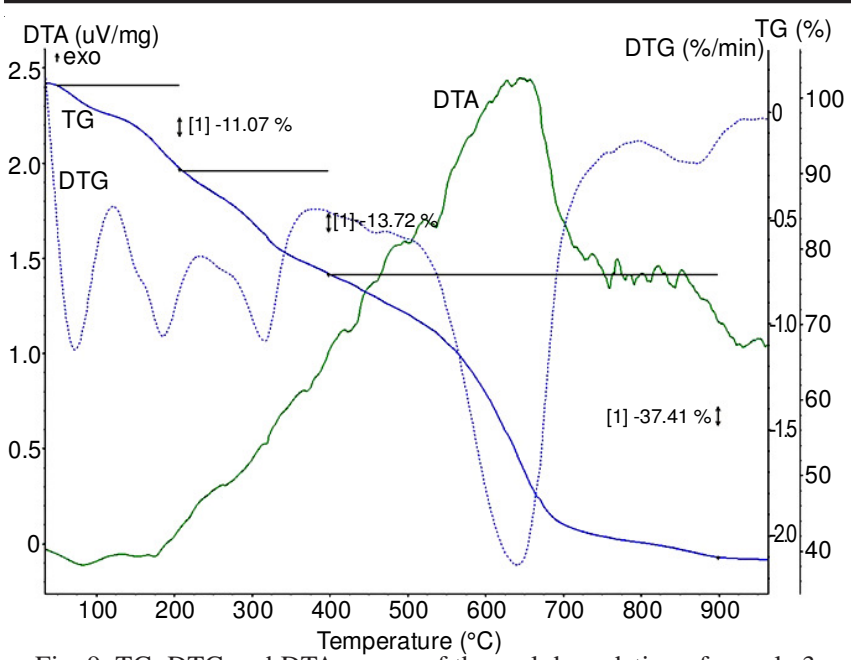

Fig. 9. TG, DTG and DTA curves of thermal degradation of sample 3

\section{Conclusion}

Flame fragmentations deposition method is economic and safe method for synthesizing of MWCNTs and FWCNTs. This study also shows that the home made instrument used in this study can be synthesized under the same condition of pressure, temperature, flow-rate of gases and time of growth of carbon nanutubes. This provides an excellent method for comparison between the activities of different types of catalysts to choose the best for using in synthesizing of carbon nanutubes in one batch.

\section{REFERENCES}

1. N.M. Mubarak, E.C. Abdullah, N.S. Jayakumar and J.N. Sahu, J. Ind Eng. Chem., 20, 1186 (2014);

https://doi.org/10.1016/j.jiec.2013.09.001.

2. C. Herrero-Latorre, J. Álvarez-Méndez, J. Barciela-García, S. GarcíaMartín and R.M. Peña-Crecente, Anal. Chim. Acta, 853, 77 (2015); https://doi.org/10.1016/j.aca.2014.10.008.

3. T.K. Gupta, B.P. Singh, R.B. Mathur and S.R. Dhakate, Nanoscale, 6 842 (2014); https://doi.org/10.1039/C3NR04565J.

4. D.M. Sun, C. Liu, W.C. Ren and H.M. Cheng, Small, 9, 1188 (2013); https://doi.org/10.1002/smll.201203154.

5. C.D. Modi, S.J. Patel, A.B. Desai and R.S.R. Murthy, J. Appl. Pharm. Sci., 1, 103 (2011).
6. K.Y. Lee, W.M. Yeoh, S.P. Chai and A.R. Mohamed, J. Nat. Gas Chem., 21, 620 (2012); https://doi.org/10.1016/S1003-9953(11)60410-6.

7. A.E. Awadallah, F.K. Gad, A.A. Aboul-Enein, M.R. Labib and A.K. Aboul-Gheit, Egyptian J. Petroleum, 22, 27 (2013); https://doi.org/10.1016/i.ejpe.2012.11.012.

8. K.Y. Tran, B. Heinrichs, J.F. Colomer, J.P. Pirard and S. Lambert, Appl. Catal. A, 318, 63 (2007); https://doi.org/10.1016/j.apcata.2006.10.042.

9. C.M. Chen, Y.M. Dai, J.G. Huang and J.M. Jehng, Carbon, 44, 1808 (2006); https://doi.org/10.1016/j.carbon.2005.12.043.

10. J. Cheng, X. Zhang, Z. Luo, F. Liu, Y. Ye, W. Yin, W. Liu and Y. Han, Mater. Chem. Phys., 95, 5 (2006); https://doi.org/10.1016/i.matchemphys.2005.04.043.

11. A.E. Awadallah, S.M. Abdel-Hamid, D.S. El-Desouki, A.A. AboulEnein and A.K. Aboul-Gheit, Egyptian J. Petroleum, 21, 101 (2012); https://doi.org/10.1016/j.ejpe.2012.11.005.

12. G.J. Muhammed and F.H. Hussein, Chem. Sci. J., 6, e110 (2015); https://doi.org/10.4172/2150-3494.1000e106.

13. G.J. Muhammed, F.H. Abdulrazzak and F.H. Hussein, Chem. Sci. J., 5, e106 (2015); https://doi.org/10.4172/2150-3494.1000e106.

14. F.H. Hussein, F.H. Abdalrazak and A. Alkaim, Patent Iraq COSQC 4975 (2017).

15. M.S. Dresselhaus, A. Jorio and R. Saito, Ann. Rev. Condens. Matter Phys., 1, 89 (2010); https://doi.org/10.1146/annurev-conmatphys-070909-103919.

16. J. Dore, A. Burian and S. Tomita, Acta Phys. Polon. A, 98, 495 (2000); https://doi.org/10.12693/APhysPolA.98.495.

17. F.H. Abdulrazzak, S.K. Esmail, H.A. Dawod, A.M. Abbas and M.K.K. Almaliki, Int. J. Theoret. Appl. Sci., 8, 37 (2016).

18. A. Szabó, C. Perri, A. Csató, G. Giordano, D. Vuono and J.B. Nagy, Materials, 3, 3092 (2010); https://doi.org/10.3390/ma3053092.

19. A.H. Jayatissa and K. Guo, Vacuum, 83, 853 (2009); https://doi.org/10.1016/j.vacuum.2008.08.009.

20. V. Datsyuk, M. Kalyva, K. Papagelis, J. Parthenios, D. Tasis, A. Siokou, I. Kallitsis and C. Galiotis, Carbon, 46, 833 (2008); https://doi.org/10.1016/j.carbon.2008.02.012.

21. E.G. Ordoñez-Casanova, M. Román-Aguirre, A. Aguilar-Elguezabal and F. Espinosa-Magaña, Materials, 6, 2534 (2013); https://doi.org/10.3390/ma6062534.

22. P. Jagdale, M. Sharon, G. Kalita, N.M.N. Maldar and M. Sharon, Adv. Mater. Phys. Chem., 2, 1 (2012); https://doi.org/10.4236/ampc.2012.21001.

23. A.B. Suriani, A.A. Azira, S.F. Nik, R.M. Nor and M. Rusop, Mater. Lett., 63, 2704 (2009); https://doi.org/10.1016/j.matlet.2009.09.048. 